\title{
Validating a bovine model for lung ultrasound of bronchiolitis
}

\author{
Paul Walsh ${ }^{1}$ (1) - Francisco R. Carvallo Chaigneau 2,4,5 Maxim Lebedev $^{2} \cdot$ Victoria Mutua $^{2} \cdot$ Heather McEligot $^{2}$. \\ Samuel H. F. Lam ${ }^{1} \cdot$ Benjamin Hwang ${ }^{2} \cdot$ Heejung Bang ${ }^{3}$ - Laurel J. Gershwin ${ }^{2}$
}

Received: 21 September 2021 / Accepted: 28 October 2021 / Published online: 24 January 2022

(C) Società Italiana di Ultrasonologia in Medicina e Biologia (SIUMB) 2021

\begin{abstract}
Purpose Bronchiolitis is a very common acute lung disease in infants caused commonly by respiratory syncytial virus (RSV). Point-of-care lung ultrasound is increasingly used in clinical care but proof that ultrasound reflects histological disease is lacking. Bovine calves are a good model for RSV bronchiolitis. We answered the following two questions: (1) does pointof-care lung ultrasound reflect lung pathology at the histological level in a bovine calf model of bronchiolitis? and (2) are point-of-care lung ultrasound images in human infants similar to those obtained in calves?

Methods We experimentally infected 24 five to six-week-old bovine calves with RSV and compared six window lung ultrasound with lung histology 10 days after inoculation. The calves were treated with antivirals and antipyretics leading to variable severity of illness. We used canonical discriminant analysis to determine if abnormal lung ultrasound findings reflected different histological findings. We compared the ultrasounds obtained from the calves with ultrasounds obtained from 10 human infants who were diagnosed clinically with bronchiolitis.

Results Canonical discriminant analysis generally demonstrated good class separation based on the maximal severity of ultrasound finding in each acoustic window. Lung ultrasound performed poorly at detecting bronchopneumonia. Bovine ultrasounds looked similar to human infant lung ultrasounds.

Conclusion Point-of-care lung ultrasound abnormalities reflect lung pathology at the histological level in a bovine calf model of bronchiolitis. Point-of-care lung ultrasound images in human infants are similar to those obtained in calves.
\end{abstract}

Keywords Bronchiolitis · Lung ultrasound · Histology $\cdot$ Respiratory syncytial virus · Translational science

Paul Walsh

yousentwhohome@gmail.com

$\triangle$ Laurel J. Gershwin

ljgershwin@ucdavis.edu

1 Pediatric Emergency Medicine, Sutter Medical Center Sacramento, 2825 Capitol Avenue, Sacramento, CA 95816, USA

2 Department of Pathology, Microbiology and Immunology, School of Veterinary Medicine, University of California, Davis, Davis, CA 95616, USA

3 Division of Biostatistics, Department of Public Health Sciences, University of California, Davis, Davis, CA 95616, USA

4 California Animal Health and Food Safety Laboratory, San Bernardino Branch, 105 W Central Ave, San Bernardino, CA 92408, USA

5 Department of Biomedical Sciences and Pathobiology, Virginia Maryland College of Veterinary Medicine, Virginia Tech, Blacksburg, VA 24060, USA

\section{Introduction}

Bronchiolitis is one of the most common causes of hospital admission in infants [1,2]. Bronchiolitis is an acute lung disease in infants caused commonly by Respiratory Syncytial Virus (RSV) [3]. Bronchiolitis is characterized clinically by increasing airway obstruction and some restriction, manifest clinically as wheezing and crackles on lung auscultation, following a period of prodromal cough and rhinorrhea. Histologically, bronchiolitis is characterized by neutrophilic and later monocytic infiltration of the alveoli, bronchioles, septae, and pleura, with associated edema and arteritis [4].

Point-of-care lung ultrasound is increasingly used in the clinical care of patients with bronchiolitis $[5,6]$. Clinical practice has moved ahead of research based on the implicit unproven assumption that lung ultrasound reflects underlying histopathological changes. Such proof is unobtainable in children. 
Animal models in general, and bovine models in particular have demonstrated their value as good immunological and histological proxies for human disease [7-11]. Bovine models of RSV are used in the ongoing development of antiviral drugs and vaccine development [12-14]. The bovine model replicates the clinical, immunological, and histological phenomena of vaccine-enhanced RSV reported in the 1960s $[15,16]$. Expanding the bovine model for point-ofcare lung ultrasound in bronchiolitis would provide additional evidence for evolving clinical practices and define the limits of what clinicians can expect to achieve using lung ultrasound.

In this first of a series of two manuscripts, we attempt to validate an experimental bovine model for point-of-care lung ultrasound in bronchiolitis. We used an experimentally infected bovine RSV model and a parallel observational human case series to answer the following questions:

1. Does point-of-care lung ultrasound reflect lung pathology at the histological level in a bovine calf model of bronchiolitis?

2. Are point-of-care lung ultrasound images in human infants similar to those obtained in our bovine calf model?

\section{Methods}

\section{Study design}

Nested (within a randomized controlled trial) cohort study for the bovine and an observational case series for the human components respectively [13].

\section{Subjects-Bovine}

We used 24 out-bred Holstein bull calves (Bos taurus) five to six weeks of age maintained in the pre-ruminant state by bottle feeding with milk replacer. The recruitment and pre-enrollment screening is described in detail elsewhere [13]. Briefly, we screened and performed nasal swabbing for RSV on unvaccinated calves at a commercial dairy to ensure they were healthy before transporting them to a climatecontrolled research barn where we observed them for 5 to 10 days before starting the study.

\section{Intervention}

We experimentally infected each animal with nebulized bovine RSV, (methods are described in detail elsewhere) [13]. The parent study was carried out in three subsets of 12 calves (total $N=36$ ). This study was conducted in the last two subsets $(N=24)$. The calves were euthanized Day
10 post-inoculation with intravenous sodium pentobarbital overdose and necropsy performed by a board-certified veterinary pathologist.

The ultrasound examinations were performed by the investigators and directly supervised undergraduate animal science students working as part of the research team. Images were obtained using either a Sunbright 150 ultrasound (Focus Technology Co., Ltd., Nanjing, Jiangsu, China) with a $7.5 \mathrm{MHz}$ curvilinear probe or a Clarius firstgeneration hand-held ultrasound machine $\mathrm{C} 73-10 \mathrm{MHz}$ curvilinear probe (Clarius Mobile Health, Burnaby, Canada).

Animals were restrained manually without a stanchion. The ultrasonographers stood or squatted to obtain the images depending on convenience and personal preference. We used three acoustic windows on each side. The probe was placed under the calves' elbows to interrogate the cranial lobes, the mid-chest at the fourth/fifth intercostal spaces to interrogate the middle (small because of the heart), and caudal aspect of the cranial lobe on the left and the middle lobe on the right. The caudal lobe was interrogated using a window between the seventh and tenth intercostal spaces. All images were interpreted in real-time by one or both of the pediatric emergency physician investigators (PW, SL).

The findings that ultrasonographers specifically sought for each window are listed in Table 1. Although all the abnormalities present were recorded, each image was assigned the most severe abnormality present in order of severity listed in Table 1.

US interpretations were recorded on paper case report forms and entered into a Filemaker 12 Pro database (Filemaker Inc, Santa Clara, CA). Each component of the study, physical examination, ultrasound, and necropsy used separate case report forms. Data management was performed using Stata 16.1 (StataCorp LLP, College Station, TX) statistical software.

At necropsy, a semi-quantitative estimate of percentage consolidation of each lobe was made. We estimated the sensitivity, specificity, and area under the curve, (AUC) for each lobe for the closest anatomical window at $20 \%$ consolidation. The choice of $20 \%$ as being a meaningful degree of consolidation was arbitrary.

We fixed sections of the right lung for at least $24 \mathrm{~h}$ in $10 \%$ formalin. The left lung was perfused with formalin at $15 \mathrm{~cm}$ water pressure prior to sections being fixed. A boardcertified veterinary pathologist reviewed all slides and made a semi-quantitative estimate of the inflammatory processes. These are summarized in Table 2. Between one and four representative slides per lobe were taken from each lobe resulting in 48 to 192 histological findings per anatomical lobe to be correlated with one acoustic window overlying a region comprising mostly but not exclusively one or two lobes depending on the window. The location of the slides is shown in Fig. 1. 
Table 1 Description and ordinal scoring of ultrasound findings in order of increasing severity (most severe at the bottom of the table)

\begin{tabular}{lll}
\hline Normal & Abnormal & $\begin{array}{l}\text { Ordinal } \\
\text { Score }\end{array}$ \\
\hline A-lines & & 0 \\
B-ines $\leq 3$ per intercostal & & 1 \\
space & B lines > 3 per intercostal space & 2 \\
& Pleural thickening & 3 \\
& Air bronchograms & 3 \\
& Multiple linear air bronchograms suggesting atelectasis & 4 \\
& Concentric air bronchograms or hepatization suggesting con- & 5 \\
& solidation & 5 \\
& Abscess & 5 \\
& Effusion & 5 \\
\hline
\end{tabular}

The ordinal numeric value played no role in the canonical discriminant analysis. Where multiple findings were present the most severe was scored

Table 2 Histological findings were sought at each level

\begin{tabular}{|c|c|c|c|c|c|}
\hline Pleura & Alveolus & Septae & Interstitium & Bronchiole & Bronchi \\
\hline Expansion & Atelectasis & Arteritis & Lymphoid nodules & $\begin{array}{l}\text { Epithelial transmigra- } \\
\text { tion }\end{array}$ & Deciliation \\
\hline Expansion edema & Edema & Edema & $\begin{array}{l}\text { Monocytic } \\
\text { thickening of the } \\
\text { interstitium }\end{array}$ & Fibrinous exudates & $\begin{array}{l}\text { Epithelial transmigra- } \\
\text { tion }\end{array}$ \\
\hline Fibrosis & Fibrinous exudate & Expansion & $\begin{array}{l}\text { PMN/Eosinophilic } \\
\text { thickening of the } \\
\text { interstitium }\end{array}$ & Inclusion bodies & Inclusion bodies \\
\hline Lymphatic dilation & Granulomas & Fibrin & Thrombosis $(*)$ & Neutrophilic exudates & Intraepithelial pustules \\
\hline $\begin{array}{l}\text { Lymphatic dilation } \\
\text { edema }\end{array}$ & Hemorrhages & Fibrosis & Vasculitis $(*)$ & Bronchiolitis obliterans & Lymphoid nodules \\
\hline Monocytic infiltrates & $\begin{array}{l}\text { Hyperplasia type II } \\
\text { pneumocytes }\end{array}$ & Monocytic infiltrates & & $\begin{array}{l}\text { Peribronchiolar lym- } \\
\text { phoid nodules }\end{array}$ & $\begin{array}{l}\text { Monocyte submucosal } \\
\text { infiltrates }\end{array}$ \\
\hline Neutrophilic infiltrates & Neutrophilic exudates & Neutrophilic infiltrates & & $\begin{array}{l}\text { Peribronchiolar mono- } \\
\text { cytic infiltrates }\end{array}$ & Neutrophilic exudates \\
\hline Pleocytic infiltrates & & Pleocytic infiltrates & & $\begin{array}{l}\text { Necrosis of epithelial } \\
\text { cells }\end{array}$ & \\
\hline \multirow[t]{3}{*}{ Thickening } & Syncytial cells & & & & \\
\hline & Lytic necrosis & & & & \\
\hline & Necrosis & & & & \\
\hline
\end{tabular}

Each item was scored on an ordinal scale 0 , none, 1 mild, 2 moderate, 3 severe except for those with an asterisk noted as being present or absent

\section{Data analysis}

\section{Gross lung pathology}

Mapping acoustic windows to lobe anatomy is inherently imprecise and complicated by practical considerations including the use of only six acoustic windows. We estimated sensitivity, specificity, and AUC for the windows and pathological specimens noted above using the diagt command in Stata [17].

\section{Histology}

We performed canonical discriminant analysis for each lobe using the last ultrasound before euthanasia as the grouping variable. Canonical discriminant analysis reduces the variables into a handful of discriminant functions [18]. These functions are the linear combination of the discriminating variables that provide maximal separation between the groups. The most informative two functions will typically explain most of the variance (often $>90 \%$ ) and can be 
Fig. 1 Schema of the bovine lung showing where the slides were taken from

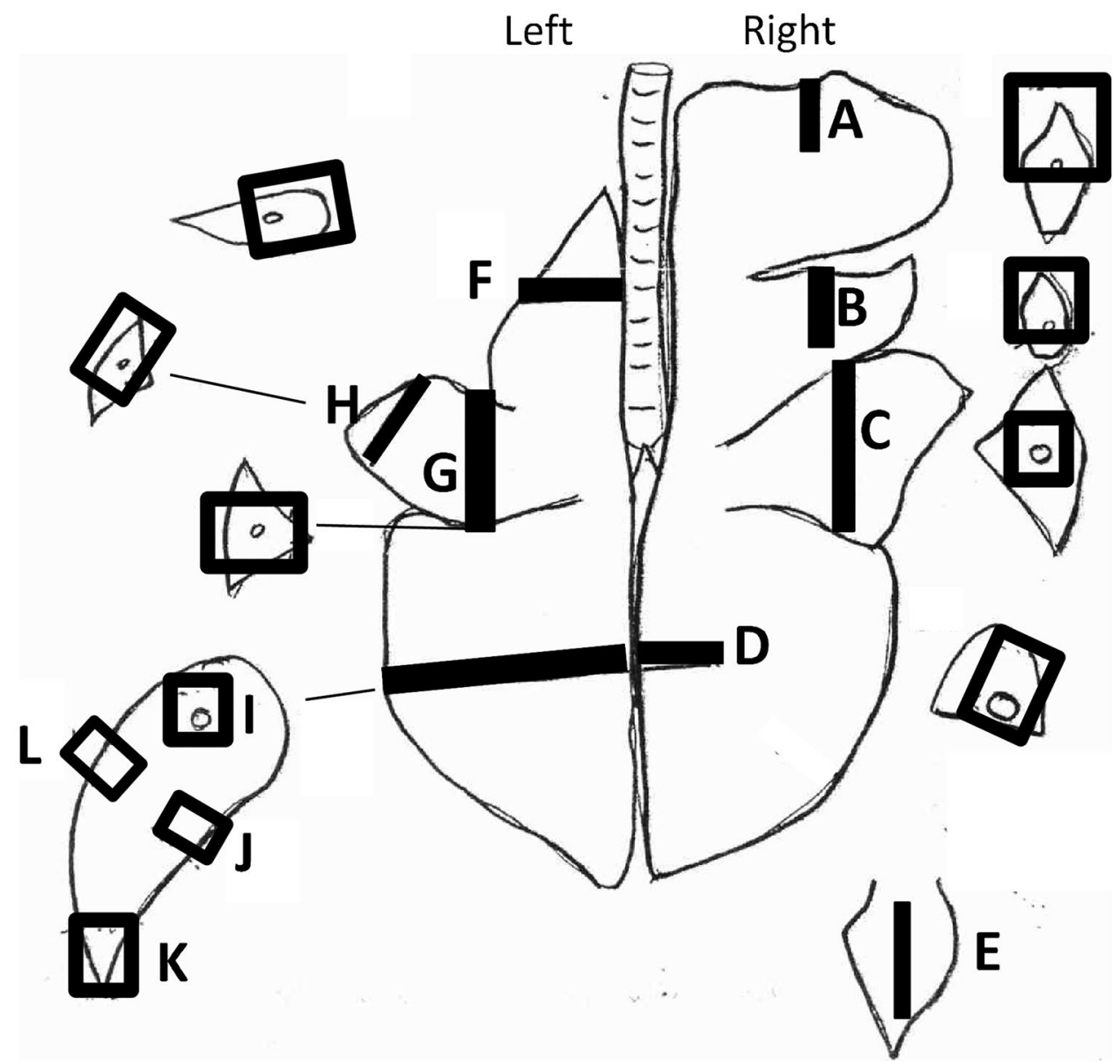

graphed onto $\mathrm{x}$ and $\mathrm{y}$ axes to demonstrate the separation between categorical groups (in this case ultrasound findings) $[18,19]$. Collinear variables and variables with only a single value were dropped from the analysis. We drew score plots from the first two discriminant functions for each lobe. The loading plots showing the contribution of each histological feature for each lobe are in the Appendix.

\section{Human case series}

This was an observational case series of 10 infants younger than six months of age who were diagnosed with bronchiolitis and had a point-of-care lung ultrasound performed in our pediatric emergency department during the 2018-2019 RSV season. These were selected from a larger ongoing study of

Table 3 Prevalence of, and diagnostic performance of ultrasound for, lobar consolidation of $20 \%$ or greater in each anatomical lobe

\begin{tabular}{|c|c|c|c|c|c|}
\hline Anatomical lobe & Prevalence $(\%)$ & Acoustic window & $\operatorname{Sen}(\%)(\mathrm{CI})$ & Spec (\%) (CI) & $\mathrm{AUC}(\mathrm{CI})$ \\
\hline Right apical cranial & 25.0 & Right cranial & $41(18-67)$ & $100(59-100)$ & $0.71(0.59-0.83)$ \\
\hline Right apical caudal & 25.0 & Right cranial & $67(22-96)$ & $83(59-96)$ & $0.75(0.53-0.97)$ \\
\hline Right intermediate & 45.8 & Right intermediate & $9(0-41)$ & $100(75-100)$ & $0.55(0.46-0.63)$ \\
\hline Right accessory & 29.2 & Right intermediate & $14(0-58)$ & $100(80-100)$ & $0.57(0.43-0.71)$ \\
\hline Right accessory & 29.2 & Right caudal & $0(0-41)$ & $88(64-99)$ & $0.44(0.36-0.52)$ \\
\hline Right diaphragmatic & 12.5 & Right caudal & $0(0-71)$ & $90(70-98)$ & $0.45(0.39-0.52)$ \\
\hline Left apical & 12.5 & Left cranial & 67 (9-99) & $81(58-95)$ & $0.74(0.40-1.00)$ \\
\hline Left intermediate & 37.5 & Left intermediate & $11(0-48)$ & $93(68-100)$ & $0.52(0.40-0.65)$ \\
\hline Left diaphragmatic & 12.5 & Left caudal & $33(1-91)$ & $95(76-100)$ & $0.64(0.31-0.97)$ \\
\hline
\end{tabular}

Calf lungs at this age are comparable in size to those of a human adult

Sen sensitivity; Spec specificity; $A U C$ area under the curve; $C I$ 95\% confidence interval 

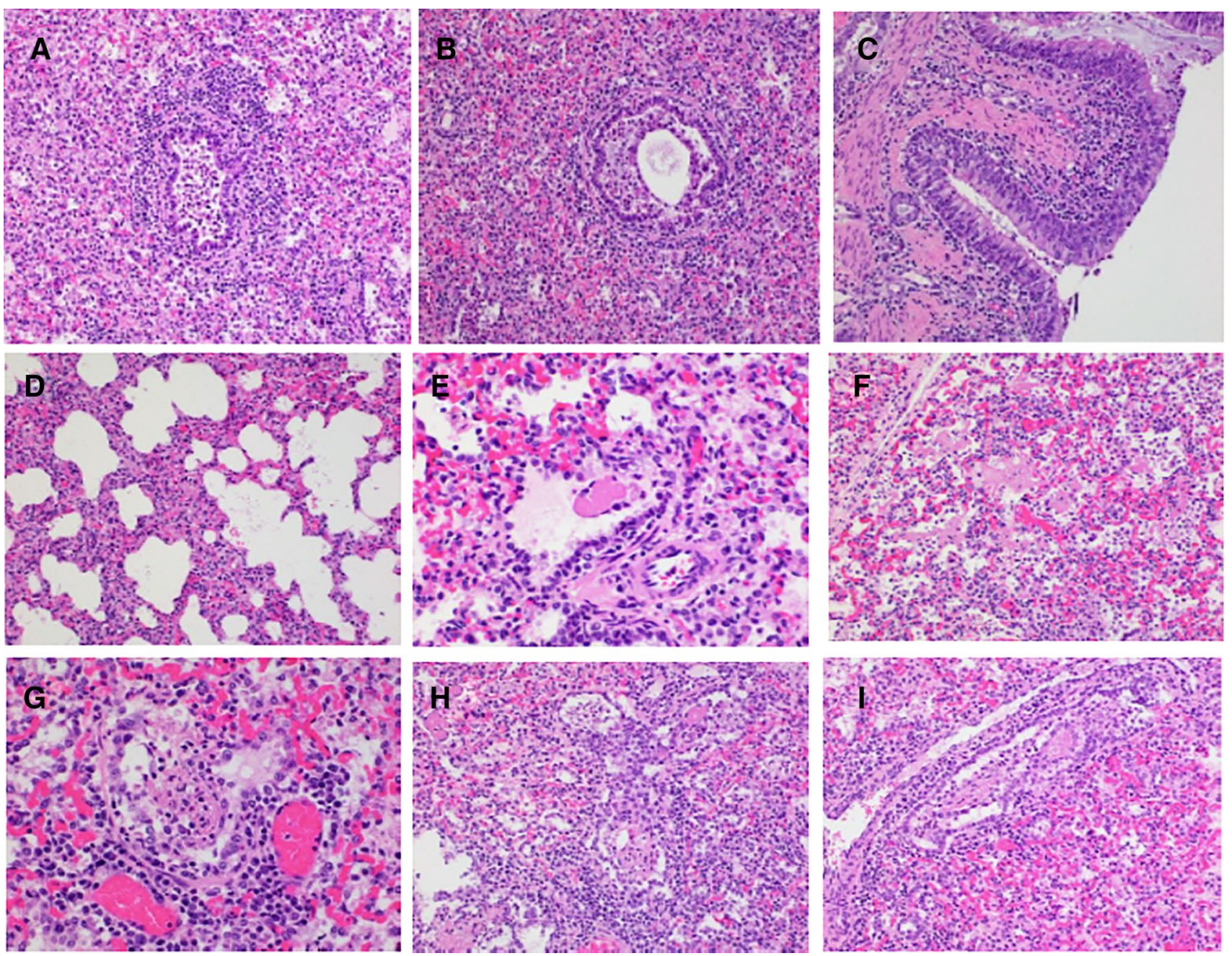

Fig. 2 Histology. A In the center, there is a bronchiole containing desquamated necrotic epithelial cells and viable and degenerate neutrophils. The periphery of the bronchiole is infiltrated with moderate numbers of lymphocytes, plasma cells, and macrophages. The rest of the pulmonary parenchyma is atelectatic, with edema and inflammatory cells within alveolar spaces. H\&E $20 \times$. B In the center, there is a bronchiole containing desquamated necrotic epithelial cells and viable and degenerate neutrophils. The periphery of the bronchiole is infiltrated with moderate numbers of lymphocytes, plasma cells, and macrophages. The rest of the pulmonary parenchyma is atelectatic, with edema and inflammatory cells within alveolar spaces. H\&E 20×. C The bronchial submucosa is moderately expanded with lymphocytes, plasma cells, and macrophages. There are a few neutrophils transmigrating through the bronchial epithelium. Within the bronchial lumen, rare neutrophils are present. H\&E 20×. D The pulmonary interstitium is moderately thickened with lymphocytes, plasma cells, and macrophages. Within the alveolar lumen, there are small amounts of a pale eosinophilic material (interpreted as edema). H\&E 20×. E Within the bronchiolar lumen, there is a small deposit of fibrin, which is lined with a few epithelial cells and macrophages. This lesion was interpreted as early bronchiolitis obliterans. H\&E 40X. F Within the alveolae lumen, there are moderate numbers of neutrophils and macrophages embedded in abundant eosinophilic fibrillary material (fibrin). The alveolar septa are moderately thickened with mononuclear cells. H\&E 20×. G The bronchiolar lumen contains moderate amounts of fibrin with few neutrophils and macrophages, which is being covered with epithelial cells. This lesion was interpreted as early bronchiolitis obliterans. H\&E $20 \times$. H The bronchiolar lumen is partially occluded with fibrin and embedded neutrophils and macrophages, all lined with small numbers of epithelial cells (interpreted as bronchiolitis obliterans). The periphery of the bronchiole is infiltrated with moderate numbers of lymphocytes and plasma cells. The adjacent alveolar septa are lined with cuboidal epithelial cells, interpreted as type II pneumocyte hyperplasia. Occasional fibrin plugs are also identified within alveolar spaces H\&E $20 \times$. I The bronchiolar lumen is partially occluded with fibrin and embedded neutrophils and macrophages (asterisk), lined with small numbers of epithelial cells (interpreted as bronchiolitis obliterans). The periphery of the bronchiole is infiltrated with moderate numbers of lymphocytes and plasma cells. The adjacent alveolar septa are atelectatic containing neutrophils and necrotic cellular debris and lined with cuboidal epithelial cells, interpreted as type II pneumocyte hyperplasia. H\&E 20×. H\&E Haematoxylin and Eosin stain. 
Fig. 3 Bovine Ultrasound.

A A-lines and normal short B-lines. B Thickened irregular pleura with abnormal B-lines. C Close irregularly place air bronchograms consistent with consolidation. D Excess B-lines
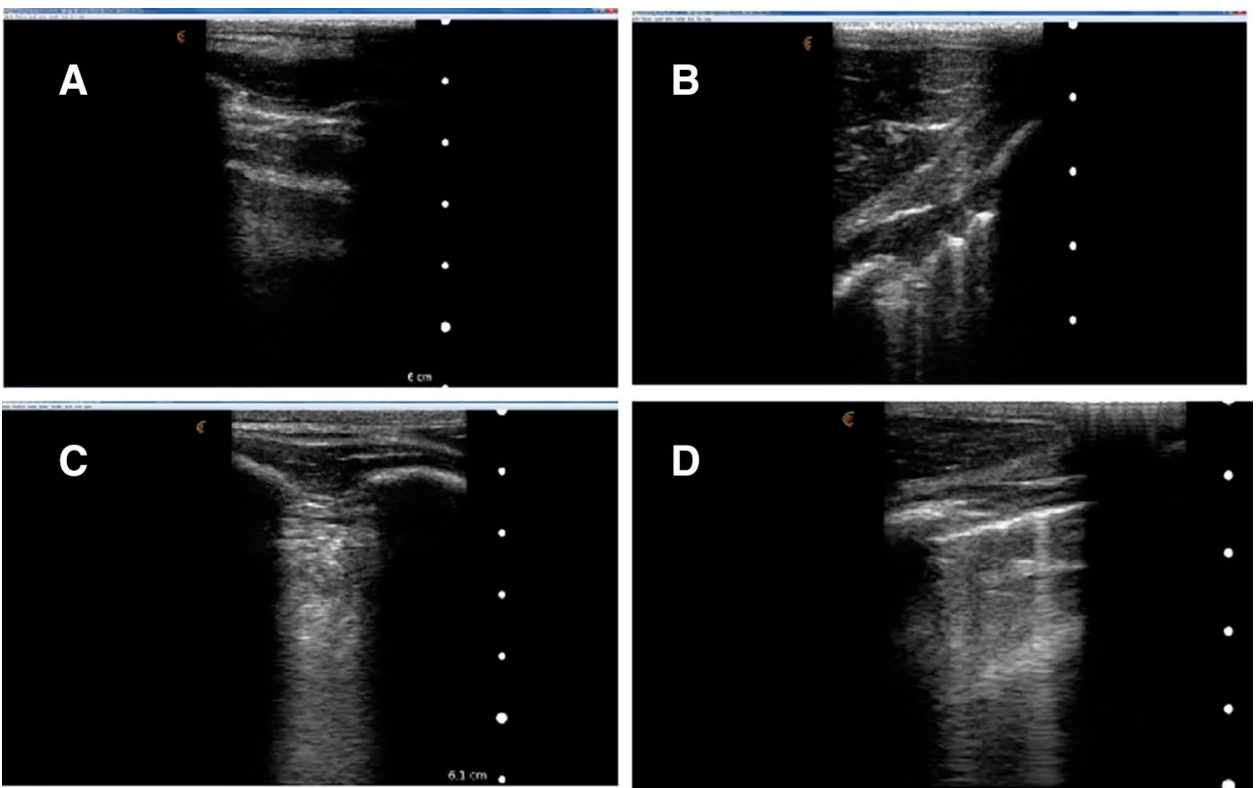

Table 4 The most important 10 components for the first factor for each lobe, and the cumulative variance explained by the top three factors (last three rows)

\begin{tabular}{|c|c|c|c|c|c|c|c|}
\hline \multirow{2}{*}{$\begin{array}{l}\text { Lung (side) } \\
\text { Finding lobe }\end{array}$} & \multicolumn{3}{|l|}{ Left } & \multicolumn{4}{|l|}{ Right } \\
\hline & Cranial & Intermediate & Diaphragmatic & Cranial cranial & Cranial caudal & Intermediate & Caudal \\
\hline Alveolus atelectasis & $\mathrm{F}$ & G & I & A & $\mathrm{B}$ & $\mathrm{C}$ & \\
\hline Alveolus edema & $\mathrm{F}$ & $\mathrm{G}$ & I & A & & & \\
\hline Alveolus fibrinous exudates & $\mathrm{F}$ & G & I & A & $\mathrm{B}$ & $\mathrm{C}$ & $\mathrm{D}$ \\
\hline Alveolus neutrophil exudates & $\mathrm{F}$ & G & $\mathrm{I}, \mathrm{J}$ & A & $\mathrm{B}$ & $\mathrm{C}$ & $\mathrm{D}$ \\
\hline Alveolus hemorrhages & & & & A & & & $\mathrm{D}$ \\
\hline \multicolumn{8}{|l|}{ Alveolus syncytial cells } \\
\hline Alveolus necrosis & & & & & $\mathrm{B}$ & $\mathrm{C}$ & \\
\hline Bronchi mononuclear infiltrates in the submucosa & $\mathrm{F}$ & G & $\mathrm{J}$ & A & & $\mathrm{C}$ & \\
\hline Bronchi neutrophilic exudates & & & & & & $\mathrm{C}$ & $\mathrm{D}$ \\
\hline Bronchioli epithelial transmigration & & & & & $\mathrm{B}$ & & \\
\hline Bronchioli fibrinous exudates & $\mathrm{F}$ & G & & & $\mathrm{B}$ & & \\
\hline Bronchioli neutrophilic exudates & $\mathrm{F}$ & G & & & B & $\mathrm{C}$ & $\mathrm{D}$ \\
\hline Bronchioli bronchiolitis obliterans & & & & A & $\mathrm{B}$ & & \\
\hline Bronchioli peribronchiolar lymph nodes & & G & & & & & \\
\hline Bronchioli peribronchiolar mononuclear infiltrates & $\mathrm{F}$ & & I & A & & & $\mathrm{D}$ \\
\hline Bronchioli necrosis of the epithelium & & & & & & $\mathrm{C}$ & \\
\hline Interstitium thickening mononuclear cells & $\mathrm{F}$ & G & I & & B & & \\
\hline Pleura fibrosis & & & & & & & $\mathrm{D}$ \\
\hline Pleura lymphatic dilation with edema & & & I & & & & $\mathrm{D}$ \\
\hline Pleura mononuclear infiltrates & & & & A & & $\mathrm{C}$ & \\
\hline Pleural thickening & & & & & & & $\mathrm{D}$ \\
\hline Septae expansion & & & I & & & $\mathrm{C}$ & \\
\hline \multicolumn{8}{|l|}{ Septae fibrosis } \\
\hline Septae mononuclear infiltrates & $\mathrm{F}$ & G & & A & $\mathrm{B}$ & & $\mathrm{D}$ \\
\hline \multicolumn{8}{|l|}{ Septae edema } \\
\hline Variance explained with 1 factor $(\%)$ & 91 & 91 & 80 & 98 & 70 & 66 & 69 \\
\hline Variance explained with 2 factors (\%) & 99 & 96 & 92 & 99 & 85 & 96 & 89 \\
\hline Variance explained with 3 factors (\%) & 100 & 99 & 97 & 100 & 97 & 99 & 94 \\
\hline
\end{tabular}

Letters indicate the slides used. The left lung was inflated with formalin prior to sectioning. The right lung was sectioned without inflation 
Canonical discriminant analysis of lung histopathology and lung ultrasound
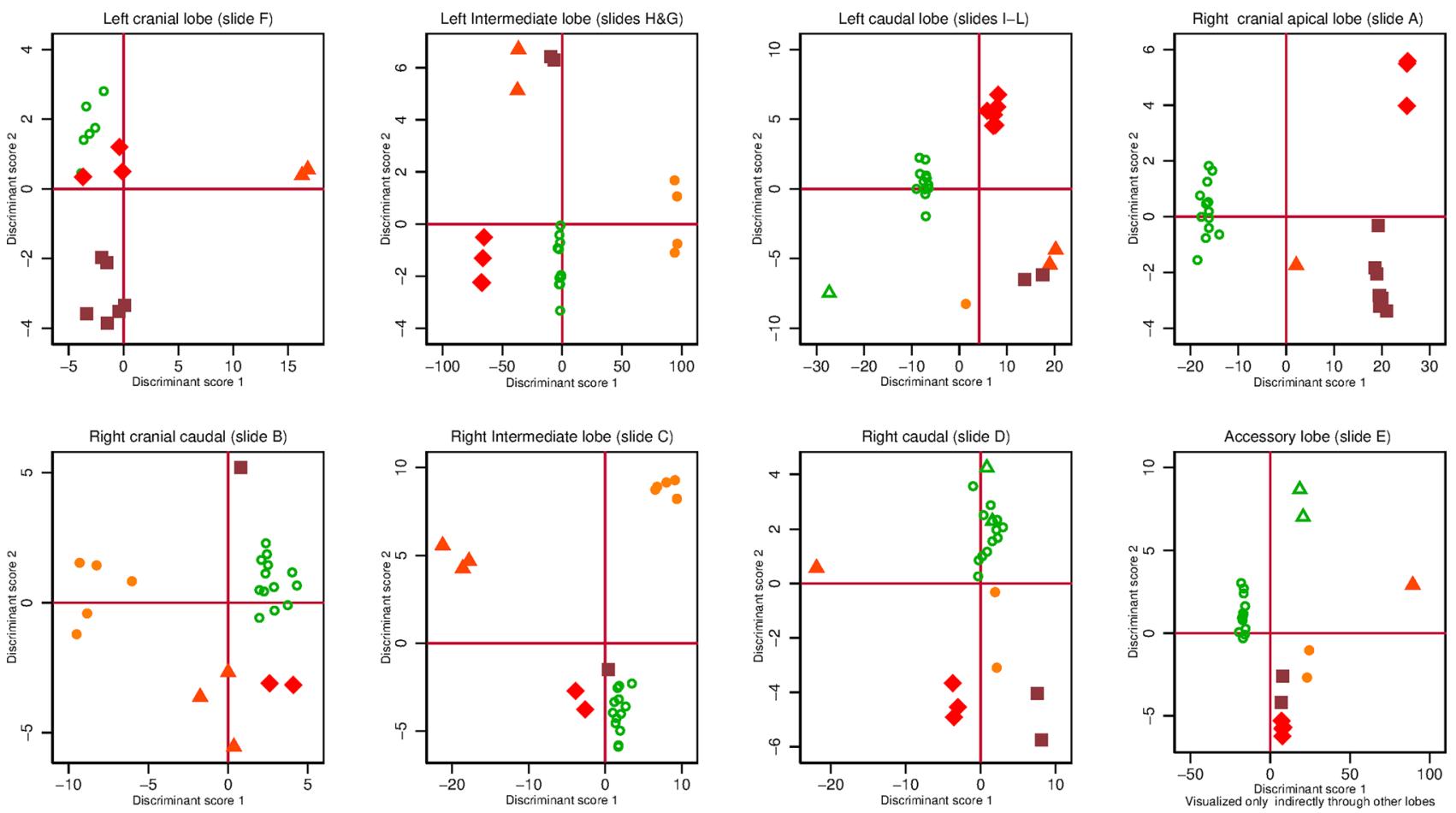

Most severe ultrasound finding

A Lines (normal)

$\Delta$ Normal $B$ lines

Abnormal B lines

Pleural thickening, Air bronchograms

Atelectasis

Consolidation

Fig. 4 Scoreplots for histopathological findings. Canonical discriminant analysis scoreplots for histopathological findings are listed in Table 4 grouped by the ultrasound results listed in Table 1. A map showing the anatomical location from where each slide was taken is shown in Fig. 1

bronchiolitis. Physical examination including lung auscultation was performed by a pediatric or general emergency physician, resident physician, or physician extender. The presence of cough, apnea, parental reported noisy breathing or wheezing, and fever were recorded. Vital signs and pulse oximetry were extracted, and lung auscultation was coded as showing wheezing/rhonchi/coarse breath sounds or crackles/ rales. The diagnosis was based on history and physical exam alone. Data were abstracted from the medical record using an electronic template.

\section{Ultrasound examination}

Ultrasounds were performed by the treating pediatric emergency physician or resident using a Zonare Z. One Pro Ultrasound machine using either a $10-5 \mathrm{MHz}$ or a $14.0 \mathrm{MHz}$ probe (Mindray North America Inc, Mahwah, NJ) or Clarius first-generation hand-held ultrasound machine $\mathrm{C} 73-10 \mathrm{MHz}$ curvilinear probe or L7 linear array probe (Clarius Mobile Health, Burnaby, Canada). The physicians performing the point-of-care lung ultrasound typically imaged the posterior acoustic windows by running the US probe down the patient's back midway between the scapula and vertebral column. Axillary and anterior windows were typically interrogated with single views of each. Physicians sometimes chose either not to interrogate or to not record findings for all possible windows if they had already reached their diagnosis.

\section{Ethical approval}

The bovine part of the study was approved by the University of California Davis Institutional Animal Care and Use Committee (authorization number 19313). Our biological 
Fig. 5 Human ultrasound images
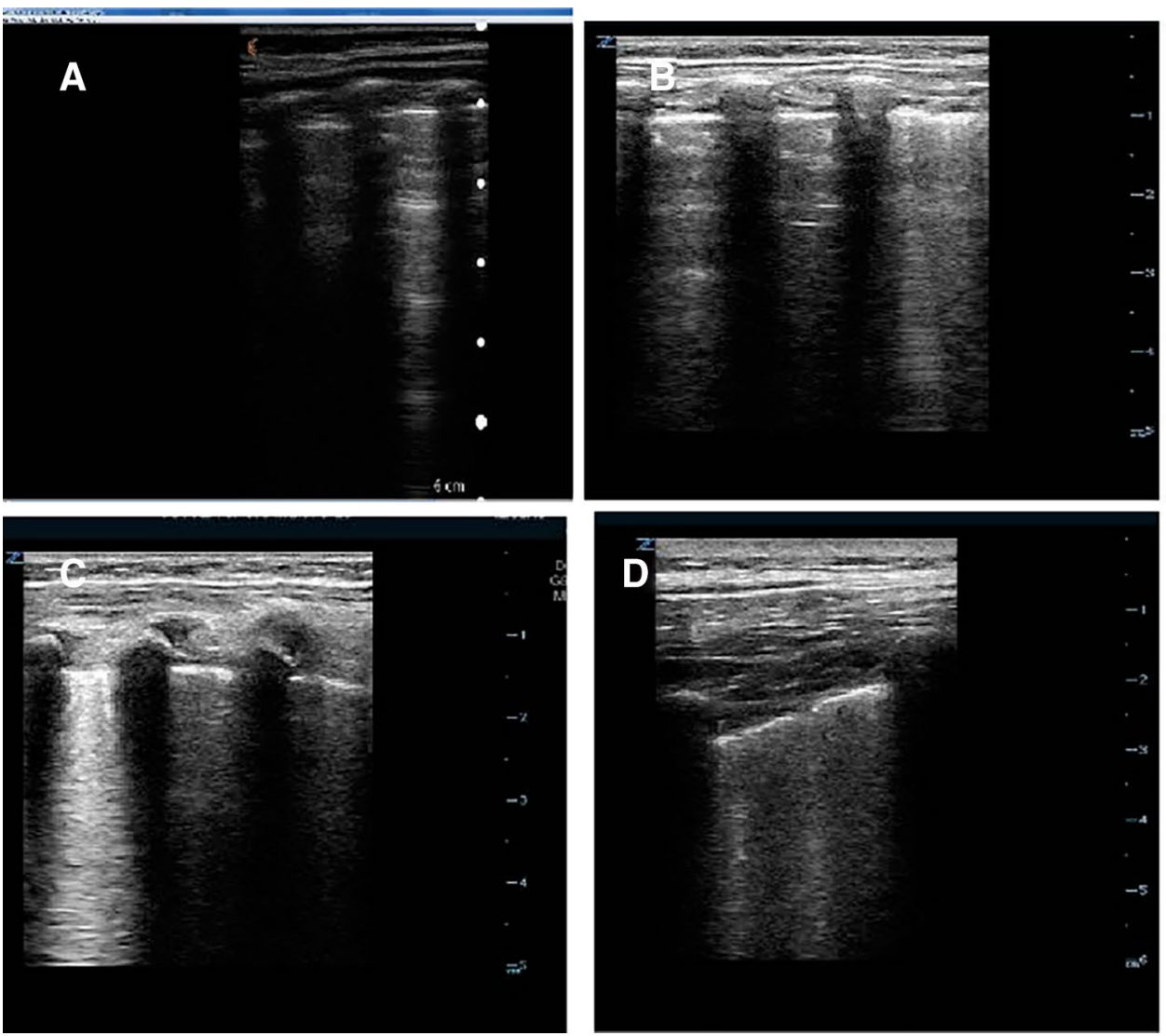

authorization use number for bovine RSV is R2323. The human part of the study was approved by the Sutter Health institutional review board, approval number 1215528-2.

\section{Results}

\section{Gross lung pathology}

We observed at least some consolidation in 115/168 (68\%) ultrasound images of lobes, in 45/48 (94\%) lungs in 23/24 (96\%) calves. The extent of individual lobar consolidation ranged from 5\% to 100\%. The cranial lobes (dependent in bovines) were the most commonly affected. Table 3 shows the prevalence of pneumonia by lung location. In general, sensitivity was very poor but specificity was good, although the small numbers lead to wide confidence intervals. The diagnostic performance of ultrasound for lobar consolidation of $20 \%$ or greater is shown in Table 3. For some anatomical lobes, the mapping to the acoustic window is imprecise. This is particularly the case for the accessory lobe.

\section{Histological findings}

One of the authors (FC) read all 288 haematoxylin and eosin-stained slides using the schema outlined above. The locations from which each slide was taken are shown in Fig. 1. Representative examples are shown in Fig. 2. There was collinearity between variables within slides and between slides when more than one slide per lobe was analyzed. Collinear variables were dropped prior to performing discriminant analysis.

Canonical discriminant analysis generally demonstrated good class separation based on the maximal severity of ultrasound finding in each acoustic window. The exception was the accessory lobe which was imaged only indirectly through the right intermediate lung window. Representative ultrasound images are shown in Fig. 3. Table 4 shows the top ten characteristics based on their contribution to factor 1 (and factor 2 to resolve ties). The score plots (Fig. 3) demonstrate separation of the most severe component of each acoustic window's ultrasound findings (Fig. 4). 


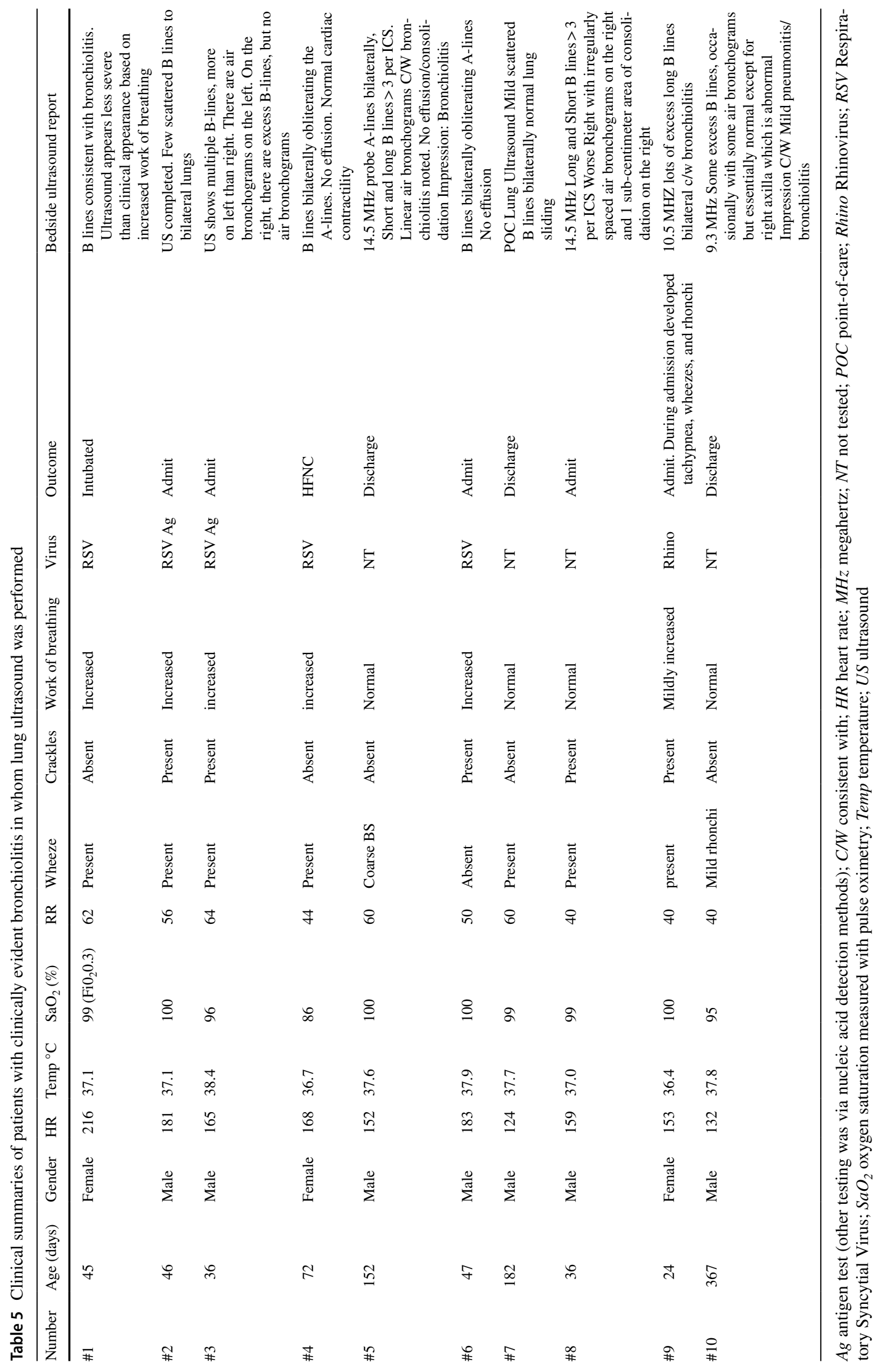




\section{Human case series}

Our convenience sample of infants with a clear-cut diagnosis of bronchiolitis showed that the point-of-care lung ultrasound images obtained from human infants and bovine calves looked very similar Fig. 5. However, treating physicians contemporaneously noted in the medical record that the severity of the lung ultrasound abnormalities was less than might be expected for a given level of respiratory distress when the predominant source of respiratory distress was bronchospasm. The human clinical and ultrasound findings are summarized in Table 5.

\section{Discussion}

We found that point-of-care lung ultrasound does reflect abnormal lung pathology at the histological level for bovine calves and that the ultrasound images obtained in the bovine model and in human infants were similar. We also found that bronchospasm may cause additional respiratory distress in children and not be apparent on lung ultrasound. This finding is somewhat at odds with Özkaya et al. but is consistent with Zoido Garrote et al. [6, 20]. Interestingly, bovids do not get asthma, although they can develop chronic cough in response to dusty environments following RSV infection. Respiratory distress improves with beta-agonists [21] (these reverse bronchospasm in infants) and beta-agonists decrease the need for hospital admission from the emergency department in bronchiolitis [22]. Children frequently develop asthma following RSV infection and bronchospasm associated with asthma manifests minimally or not at all on lung ultrasound. Consequently, our data show that ultrasound cannot replace auscultation in the evaluation of bronchiolitis.

Validation of lung ultrasound has been challenging. Unlike other body areas lung ultrasound is heavily based on the interpretation of artifacts rather than direct visualization. This is partly because ultrasound waves are poorly transmitted through air and the lung is an air-filled structure, and partly because the structure of the lung attenuates ultrasound waves by an order of magnitude more than air alone [23]. Chest X-rays are of limited value in general because the clinical findings of pneumonia can precede $\mathrm{x}$-ray findings by a few days, and in bronchiolitis in particular because physicians realized early that chest $\mathrm{X}$-rays are inferior to ultrasound imaging for peripheral lesions such as those seen in bronchiolitis [24, 25]. CT has been used as a gold standard for SARS-COV-2 infection. The SARS-CoV-2 pandemic has demonstrated the validity of US for peripheral lesions
[26]. SARS-CoV-2 however represents the optimum use case scenario for lung ultrasound. The lesions are mostly alveolar and peripheral. The distribution of the infection in bronchiolitis is more complex than SARS-CoV-2 and there is neither a tradition nor clinical justification for obtaining chest CT scans in clinical practice. This is particularly true in children where the radiation would cause harm.

Unlike cases of childhood malignancy or empyema, axial imaging by MRI or human tissue biopsy will almost never be available to validate lung ultrasound findings [27-31].

Comparing ultrasound and histopathological findings addressed both the issue of validity and patient-centeredness of a tissue-based gold standard. Using a bovine calf model addresses concerns that the size of cotton rat models would provide unrealistically high-quality images compared with human practice. Moreover, bovine RSV is native to calves and may lead to a greater range of disease severity than infecting cotton rats with human RSV. Using histology to validate ultrasound findings brought its own challenges. Simple correlation between specific ultrasound and histological findings is limited by the sheer number and range of histological findings associated with infection. Canonical discriminant analysis achieved dimension reduction and visual display of the differences between groups. This allowed us to determine that lung ultrasound was distinguishing different histopathological states. However, because of dimension reduction, each value on the $\mathrm{x}$ and $\mathrm{y}$ axes represents a 'union' of variables rather than any single histological characteristic [32]. Canonical discriminant analysis risks instability with smaller sample sizes. Table 4 shows the top ten features for each lobe analyzed separately using canonical discriminant analysis and shows a reassuring amount of overlap between the results for each lobe.

\section{Limitations}

A clear limitation of the limited six view protocol we used in calves was its inability to reliably detect broncho-pneumonia which lay too deep for consistent detection. Such a limitation is likely to hold for larger children depending on the probe used. We did not measure inter-rater reliability. Our sample sizes were also small although at or close to the limit of the practicalities of large animal research. 

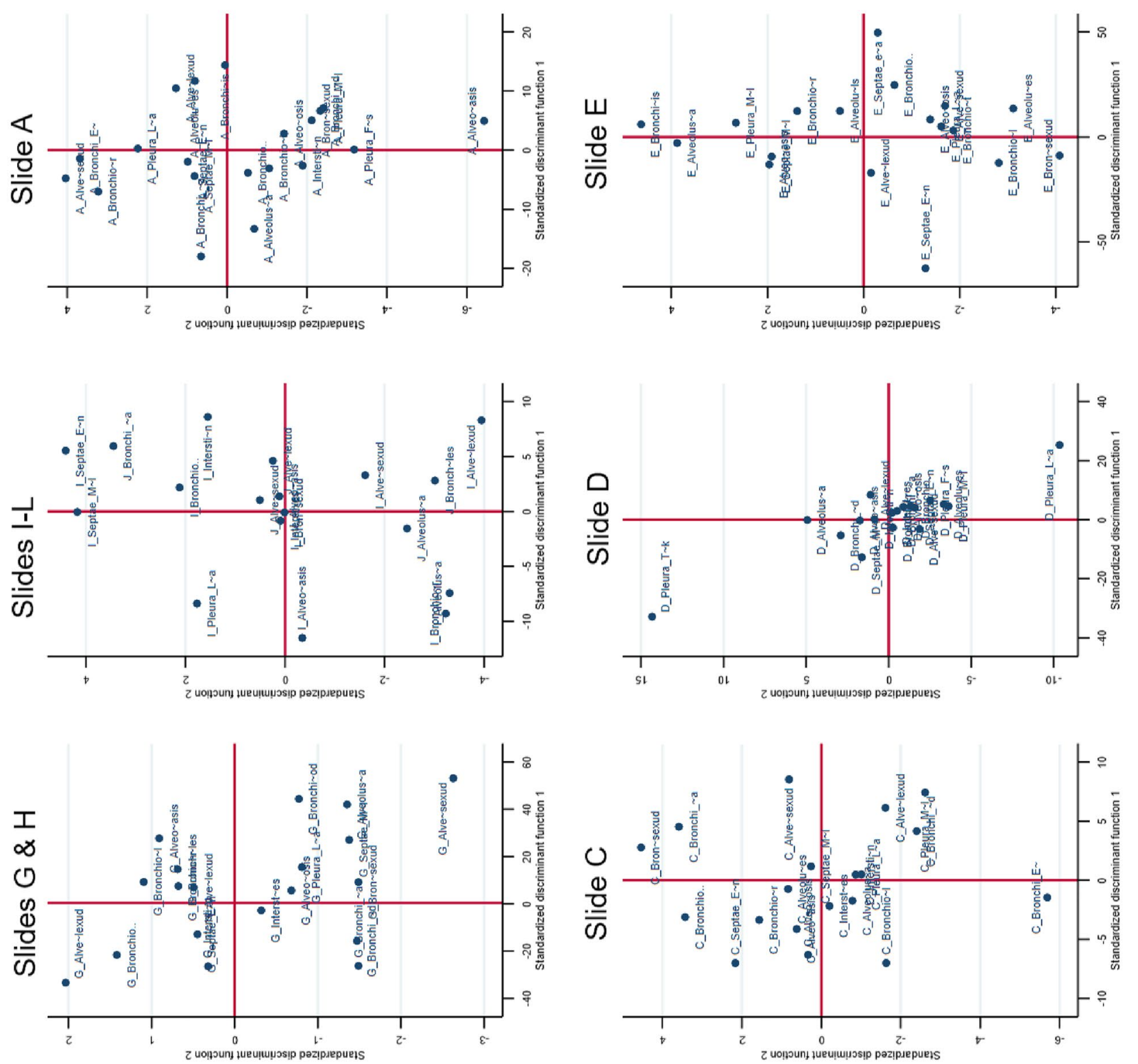

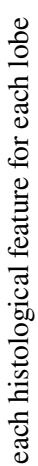
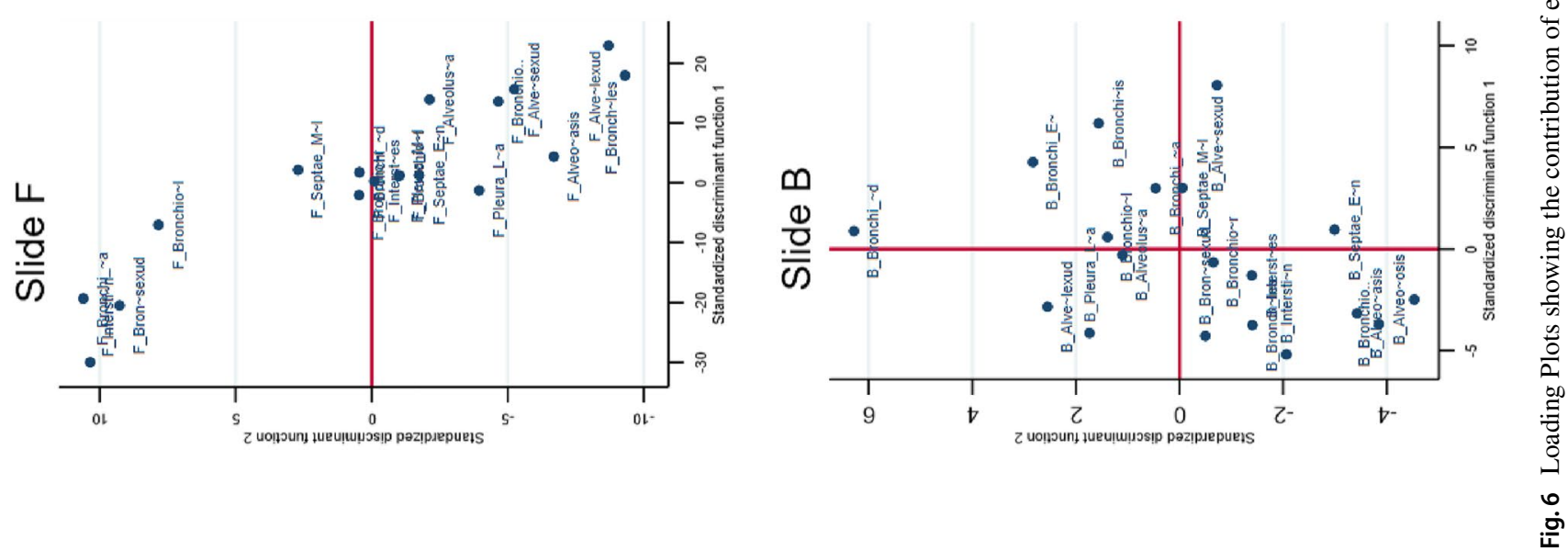
Fig. 7 Map of the bovine lung showing from where each slide is taken

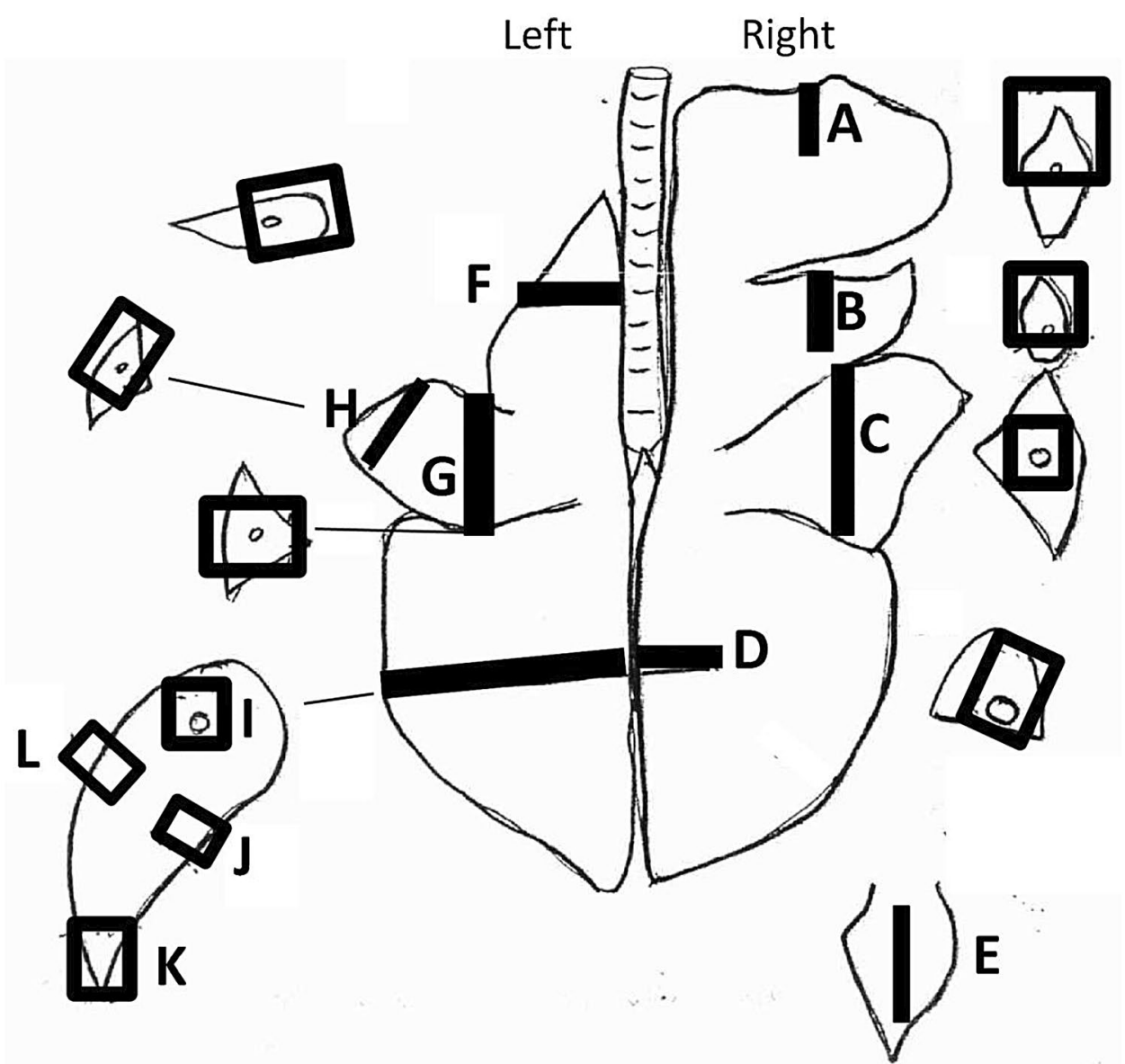

\section{Conclusion}

Point-of-care lung ultrasound abnormalities reflect lung pathology at the histological level in a bovine calf model of bronchiolitis. Point-of-care lung ultrasound images in human infants appear similar to those obtained in our bovine calf model.

\section{Appendix}

See Figs. 6 and 7.

Acknowledgements The authors wish to acknowledge the following, Ron Dickerson, for ultrasound technical support, Andrea Hankins, Data Steward at Sutter Institute for Medical Research and our undergraduate student assistants, particularly: Nazleen Mohseni, Katrina Miller, Caroline Barry, Leticia Charco, Alexandra Chapman, Megan Wells, Miranda Leung.

Funding Funding for this research was from The United States Department of Agriculture, National Institute for Food Animals- grant \#201611003 awarded to LG and PW (Dual purpose dual benefit initiative), by UL1 TR001860 from the National Institutes of Health's National
Center for Advancing Translational Sciences (HB) and The Pediatric Emergency Medicine Research Foundation.

Availability of data and material The data files for the calves are attached. The medical records of the patients involved in the study are not. For auditing purposes, patient identifiers are accessible to the authors for the duration of the ongoing studies and the institutional review board indefinitely via a Sutter-approved data steward.

Code availability Code to replicate the analyses from the cleaned data file is attached. DOI: 10.5281/zenodo.5784499

\section{Declarations}

Conflict of interest None.

Ethical approval Ethics approval was obtained from the institutional review boards, (Sutter Medical Center), institutional animal care and use committee, and biological use authorization for live virus use (UC Davis, veterinary school).

Consent to participate A waiver of consent was obtained for human patients from the institutional review and privacy boards, (Sutter Medical Center).

Consent for publication All authors agree to the publication of this manuscript. 


\section{References}

1. Leader S, Kohlhase K (2003) Recent trends in severe respiratory syncytial virus (RSV) among US infants, 1997 to 2000. J Pediatr 143:127-132. https://doi.org/10.1067/S0022-3476(03)00510-9

2. Shi T, McAllister DA, O'Brien KL, Simoes EAF, Madhi SA, Gessner BD, Polack FP, Balsells E, Acacio S, Aguayo C, Alassani I, Ali A, Antonio M, Awasthi S, Awori JO, Azziz-Baumgartner E, Baggett HC, Baillie VL, Balmaseda A, Barahona A, Basnet S, Bassat Q, Basualdo W, Bigogo G, Bont L, Breiman RF, Brooks WA, Broor S, Bruce N, Bruden D, Buchy P, Campbell S, Carosone-Link P, Chadha M, Chipeta J, Chou M, Clara W, Cohen C, de Cuellar E, Dang DA, Dash-Yandag B, Deloria-Knoll M, Dherani M, Eap T, Ebruke BE, Echavarria M, de Freitas Lázaro Emediato CC, Fasce RA, Feikin DR, Feng L, Gentile A, Gordon A, Goswami D, Goyet S, Groome M, Halasa N, Hirve S, Homaira N, Howie SRC, Jara J, Jroundi I, Kartasasmita CB, Khuri-Bulos N, Kotloff KL, Krishnan A, Libster R, Lopez O, Lucero MG, Lucion F, Lupisan SP, Marcone DN, McCracken JP, Mejia M, Moisi JC, Montgomery JM, Moore DP, Moraleda C, Moyes J, Munywoki P, Mutyara K, Nicol MP, Nokes DJ, Nymadawa P, da CostaOliveira MT, Oshitani H, Pandey N, Paranhos-Baccalà G, Phillips LN, Picot VS, Rahman M, Rakoto-Andrianarivelo M, Rasmussen ZA, Rath BA, Robinson A, Romero C, Russomando G, Salimi V, Sawatwong P, Scheltema N, Schweiger B, Scott JAG, Seidenberg P, Shen K, Singleton R, Sotomayor V, Strand TA, Sutanto A, Sylla M, Tapia MD, Thamthitiwat S, Thomas ED, Tokarz R, Turner C, Venter M, Waicharoen S, Wang J, Watthanaworawit W, Yoshida LM, Yu H, Zar HJ, Campbell H, Nair H, Network RSV Global Epidemiology (2017) Global, regional, and national disease burden estimates of acute lower respiratory infections due to respiratory syncytial virus in young children in 2015: a systematic review and modelling study. Lancet 390:946-958. https://doi.org/ 10.1016/S0140-6736(17)30938-8

3. Mansbach JM, Piedra PA, Teach SJ, Sullivan AF, Forgey T, Clark S, Espinola JA, Camargo CA Jr, MARC-30 Investigators (2012) Prospective multicenter study of viral etiology and hospital length of stay in children with severe bronchiolitis. Arch Pediatr Adolesc Med 166:700-706. https://doi.org/10.1001/archpediatrics.2011. 1669

4. Johnson JE, Gonzales RA, Olson SJ, Wright PF, Graham BS (2007) The histopathology of fatal untreated human respiratory syncytial virus infection. Mod Pathol 20:108-119. https://doi.org/ 10.1038/modpathol.3800725

5. Supino MC, Buonsenso D, Scateni S, Scialanga B, Mesturino MA, Bock C, Chiaretti A, Giglioni E, Reale A, Musolino AM (2019) Point-of-care lung ultrasound in infants with bronchiolitis in the pediatric emergency department: a prospective study. Eur J Pediatr 178:623-632. https://doi.org/10.1007/s00431-019-03335-6

6. Özkaya AK, Yilmaz HL, Kendir ÖT, Gökay SS, Eyüboğlu İ (2020) Lung ultrasound findings and bronchiolitis ultrasound score for predicting hospital admission in children with acute bronchiolitis. Pediatr Emerg Care 36:e135-e142. https://doi.org/ 10.1097/PEC.0000000000001705

7. Sacco RE, McGill JL, Palmer MV, Lippolis JD, Reinhardt TA, Nonnecke BJ (2012) Neonatal calf infection with respiratory syncytial virus: drawing parallels to the disease in human infants. Viruses 4:3731-3753. https://doi.org/10.3390/v4123731

8. Guerra-Maupome M, Palmer MV, McGill JL, Sacco RE (2019) Utility of the neonatal calf model for testing vaccines and intervention strategies for use against human RSV infection. Vaccines (Basel). https://doi.org/10.3390/vaccines7010007

9. Taylor G (2013) Bovine model of respiratory syncytial virus infection. Curr Top Microbiol Immunol 372:327-345. https://doi.org/ 10.1007/978-3-642-38919-1_16
10. Meyerholz DK, Grubor B, Fach SJ, Sacco RE, Lehmkuhl HD, Gallup JM, Ackermann MR (2004) Reduced clearance of respiratory syncytial virus infection in a preterm lamb model. Microbes Infect 6:1312-1319. https://doi.org/10.1016/j.micinf.2004.08.006

11. Richardson JY, Ottolini MG, Pletneva L, Boukhvalova M, Zhang S, Vogel SN, Prince GA, Blanco JC (2005) Respiratory syncytial virus (RSV) infection induces cyclooxygenase 2 : a potential target for RSV therapy. J Immunol 174:4356-4364. https://doi.org/10. 4049/jimmunol.174.7.4356

12. Jordan R, Shao M, Mackman RL, Perron M, Cihlar T, Lewis SA, Eisenberg EJ, Carey A, Strickley RG, Chien JW, Anderson ML, McEligot HA, Behrens NE, Gershwin LJ (2015) Antiviral efficacy of a respiratory syncytial virus (RSV) fusion inhibitor in a bovine model of RSV infection. Antimicrob Agents Chemother 59:4889-4900. https://doi.org/10.1128/AAC.00487-15

13. Walsh P, Lebedev M, McEligot H, Mutua V, Bang H, Gershwin LJ (2020) A randomized controlled trial of a combination of antiviral and nonsteroidal anti-inflammatory treatment in a bovine model of respiratory syncytial virus infection. PLoS ONE 15:e0230245. https://doi.org/10.1371/journal.pone.0230245

14. Gershwin LJ, Behrens NE, McEligot HA, Carvallo-Chaigneau FR, Crum LT, Gunnarson BM, Corbeil LB (2017) A recombinant subunit vaccine for bovine RSV and Histophilus somni protects calves against dual pathogen challenge. Vaccine 35:1954-1963. https://doi.org/10.1016/j.vaccine.2017.01.059

15. Gershwin LJ, Schelegle ES, Gunther RA, Anderson ML, Woolums AR, Larochelle DR, Boyle GA, Friebertshauser KE, Singer RS (1998) A bovine model of vaccine enhanced respiratory syncytial virus pathophysiology. Vaccine 16:1225-1236. https://doi.org/10. 1016/S0264-410X(98)80123-0

16. Kim HW, Canchola JG, Brandt CD, Pyles G, Chanock RM, Jensen K, Parrott RH (1969) Respiratory syncytial virus disease in infants despite prior administration of antigenic inactivated vaccine. Am J Epidemiol 89:422-434. https://doi.org/10.1093/oxfordjournals. aje.a120955

17. Seed P (2001) DIAGT: Stata module to report summary statistics for diagnostic tests compared to true disease status. Statistical Software Components S423401, Boston College Department of Economics, revised 19 Feb 2010. Last Accessed 15 Dec 2021

18. Rencher AC (1992) Interpretation of canonical discriminant functions, canonical variates, and principal components. Am Stat 46:217-225. https://doi.org/10.2307/2685219

19. Statacorp (2019) Stata multivariate statistics reference manual release 16. Statacorp, College Station, Texas

20. Zoido Garrote E, García Aparicio C, Camila Torrez Villarroel C, Pedro Vega García A, Muñiz Fontán M, Oulego Erroz I (2019) Usefulness of early lung ultrasound in acute mild-moderate acute bronchiolitis. A pilot study. An Pediatr 90:10-18. https://doi.org/10.1016/j.anpedi.2018.03.002

21. Ralston SL, Lieberthal AS, Meissner HC, Alverson BK, Baley JE, Gadomski AM, Johnson DW, Light MJ, Maraqa NF, Mendonca EA, Phelan KJ, Zorc JJ, Stanko-Lopp D, Brown MA, Nathanson I, Rosenblum E, Sayles S, Hernandez-Cancio S (2014) Clinical practice guideline: the diagnosis, management, and prevention of bronchiolitis. Pediatrics. https://doi.org/10. 1542/peds.2014-2742

22. Walsh P, Caldwell J, McQuillan KK, Friese S, Robbins D, Rothenberg SJ (2008) Comparison of nebulized epinephrine to albuterol in bronchiolitis. Acad Emerg Med 15:305-313. https:// doi.org/10.1111/j.1553-2712.2008.00064.x

23. Dunn F, Fry WJ (1961) Ultrasonic absorption and reflection by lung tissue. Phys Med Biol 5:401-410. https://doi.org/10.1088/ 0031-9155/5/4/302

24. Caiulo VA, Gargani L, Caiulo S, Fisicaro A, Moramarco F, Latini G, Picano E (2011) Lung ultrasound in bronchiolitis: 
comparison with chest X-ray. Eur J Pediatr 170:1427-1433. https://doi.org/10.1007/s00431-011-1461-2

25. Jaszczołt S, Polewczyk T, Dołęga-Kozierowska M, Woźniak M, Doniec Z (2018) Comparison of lung ultrasound and chest X-ray findings in children with bronchiolitis. J Ultrason 18:193-197. https://doi.org/10.15557/JoU.2018.0029

26. Walsh P, Hankins A, Bang H (2020) Point-of-care lung ultrasound is useful to evaluate emergency department patients for COVID-19. West J Emerg Med 21:24-31. https://doi.org/10. 5811/westjem.2020.8.49205

27. Brillantino C, Rossi E, Pirisi P, Gaglione G, Errico ME, Minelli R, Menna BF, Zeccolini R, Zeccolini M (2021) Pseudopapillary solid tumour of the pancreas in paediatric age: description of a case report and review of the literature. J Ultrasound. https://doi. org/10.1007/s40477-021-00587-7

28. Tufano A, Flammia RS, Antonelli L, Minelli R, Franco G, Leonardo C, Cantisani V (2021) The value of contrast-enhanced ultrasound (CEUS) in differentiating testicular masses: a systematic review and meta-analysis. NATO Adv Sci Inst Ser E Appl Sci 11:8990. https://doi.org/10.3390/app11198990
29. Brillantino C, Rossi E, Minelli R, Bifano D, Baldari D, Pizzicato P, Zeccolini R, Zeccolini M (2021) Mediastinal thymoma: a difficult diagnosis in the pediatric age. Radiol Case Rep 16:2579-2585

30. Brillantino C, Rossi E, Minelli R, Irace D, Castelli L, Zeccolini R, Bignardi E, Tufano A (2019) A rare case of renal tumor in children: clear cell sarcoma. G Chir 40:217-224

31. Brillantino C, Rossi E, Bifano D, Minelli R, Tamasi S, Mamone R, Bignardi E, Zeccolini R, Zeccolini M, Vallone G (2020) An unusual onset of pediatric acute lymphoblastic leukemia. J Ultrasound. https://doi.org/10.1007/s40477-020-00461-y

32. Cruz-Castillo JG, Ganeshanandam S, MacKay BR, Lawes GS, Lawoko CRO, Woolley DJ (1994) Applications of canonical discriminant analysis in horticultural research. Hortic Sci 29:1115-1119

Publisher's Note Springer Nature remains neutral with regard to jurisdictional claims in published maps and institutional affiliations. 